\title{
Microstructural Characterization Al-Cu-Mg-WC Composite Powders Prepared by Mechanical Alloying
}

G. Rodríguez-Cabriales ${ }^{1}$, A.M. Lometo-Sánchez ${ }^{2}$ I. Estrada-Guel ${ }^{1}$, C.G. Garay-Reyes ${ }^{1}$, M. C. Maldonado-Orozco ${ }^{2}$, R. Martínez-Sánchez ${ }^{1}$

${ }^{1}$ Centro de Investigación en Materiales Avanzados (CIMAV), Laboratorio Nacional de Nanotecnología, Miguel de Cervantes No. 120, 31136, Chihuahua, Chih., México.

${ }^{2}$ Universidad Autónoma de Chihuahua (UACH), Facultad de Ingeniería, Circuito No. 1, Nuevo Campus Universitario, CP 31125 Chihuahua, Chih., México.

The Al-Cu-Mg alloys present excellent properties, such as tensile strength, excellent stability thermal and yield strength [1]. Nowadays, these alloys are amply used in aeronautic industry and they are considered for future applications where processing of these materials are highly important. Its main hardening mechanism is due to precipitation caused by ternary system $\mathrm{Al}-\mathrm{Cu}-\mathrm{Mg}$. On the other hand, there is a great interest toward ceramic particle-reinforced metal-matrix composites to enhance mechanical properties. Aluminum matrix composites are outstanding examples of it. An excellent candidate to reinforce this composite is tungsten carbide (WC) due to its high hardness, high strength, good chemical stability and better resistance at high temperature [2]. The aim of this work is synthetize Al-Cu-Mg-WC composite powders by mechanical alloying (MA) and heir microstructural characterization.

The composite powders were fabricated by mixing simultaneously elemental powder in the appropriate percentage to obtain chemical composition of $\mathrm{Al}-4 \mathrm{Cu}-1.5 \mathrm{Mg}$ alloy with $1 \mathrm{wt} \%$ of WC. The process of MA was carried out in a high energy mill (Spex-8000) during 3 and $5 \mathrm{~h}$ in an argon atmosphere. The milling device and milling media used in the experiments were made from hardened steel. The milling ball-to-powder ratio was 5 to 1, methanol was added as process control agent. The microstructural characterization was realized by scanning electron microscopy and structural characterization was determined by X-ray diffraction. A SEM Hitachi model SU3500 and PANalytical X'Pert PRO diffractometer was used for different characterizations. The crystallite size was determined by Scherrer formula.

The Fig. 1 shows changes in the particle size in function of milling time (mt) due to processes of MA. The micrographs 1a-f show the evolution of the morphology as a function of mt. The Fig. 2 a) shows XRD diffractograms of powders at different $\mathrm{mt}$, it is appreciated a decrease the intensity of characteristic peaks of $\mathrm{Al}$ and $\mathrm{Cu}$ phases in function of $\mathrm{mt}$, in addition to broadened of these peaks. The characteristic peaks of WC phase did not suffer change. The Fig. 2 b) presents crystallite size and lattice parameter according to $\mathrm{mt}$, it is observed decreases in crystallite size and lattice parameter due to probably to formation of $\mathrm{Al}-\mathrm{Cu}$ solid solution. It is concluded that is possible fabricate $\mathrm{Al}-\mathrm{Cu}-\mathrm{Mg}-\mathrm{WC}$ composite powders by MA with homogeneous distribution of WC.

References:

[1] C.G. Garay-Reyes, L. González-Rodelas, E. Cuadros-Lugo, E. Martínez-Franco, J. AguilarSantillan, I. Estrada-Guel, M.C. Maldonado-Orozco, R. Martínez-Sánchez, J Alloys Compd 705 (2017) p. 1-8.

[2] K. Ravikumar, K. Kiran, V.S. Sreebalaji, Measurement 102 (2017), p. 142-149. 

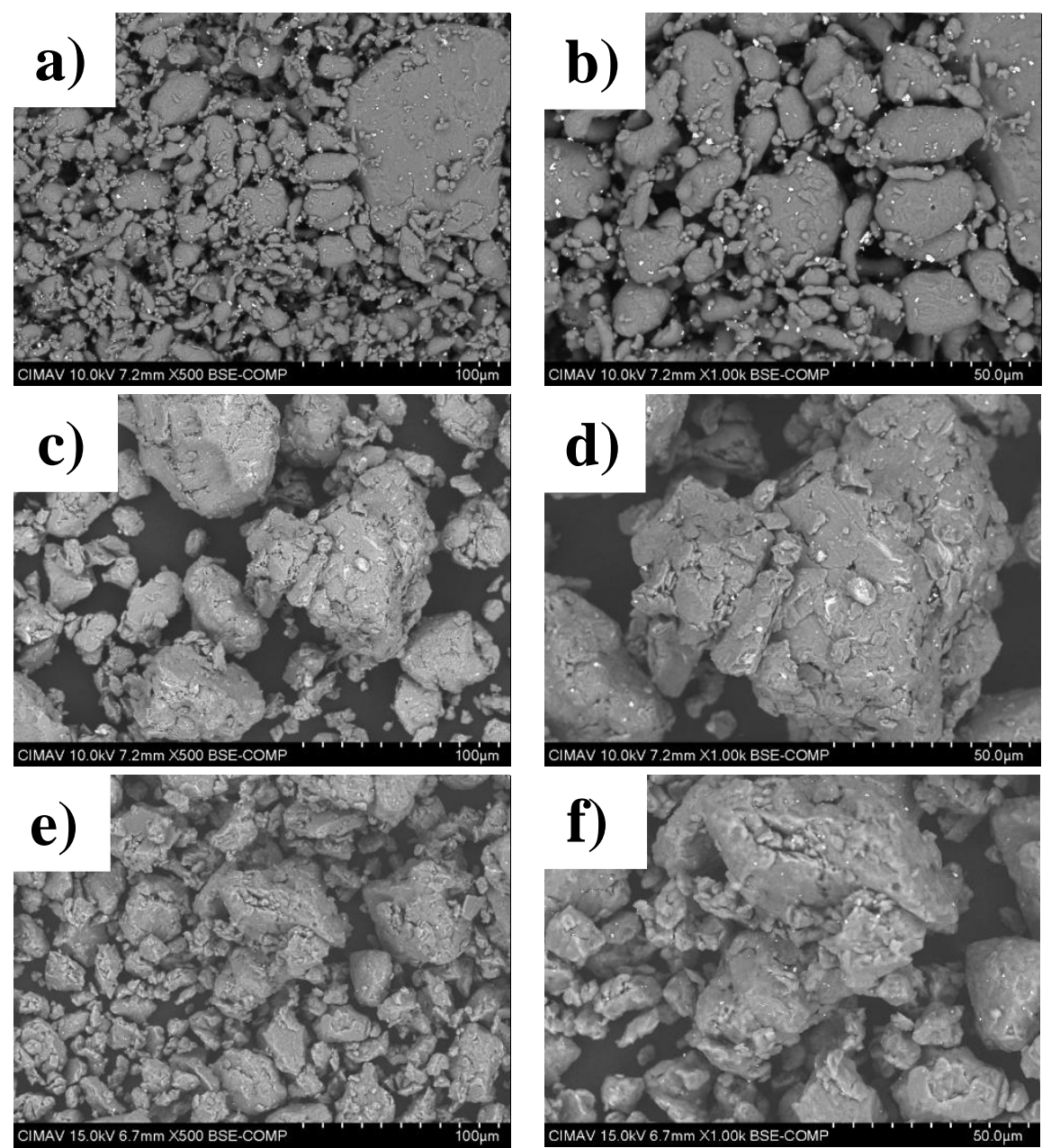

Figure 1. SEM Micrographs obtained from Al-Cu-Mg-WC alloy powder after a,b) 0 h, c,d) 3 h and e,f) $5 \mathrm{~h}$ of $\mathrm{mt}$.
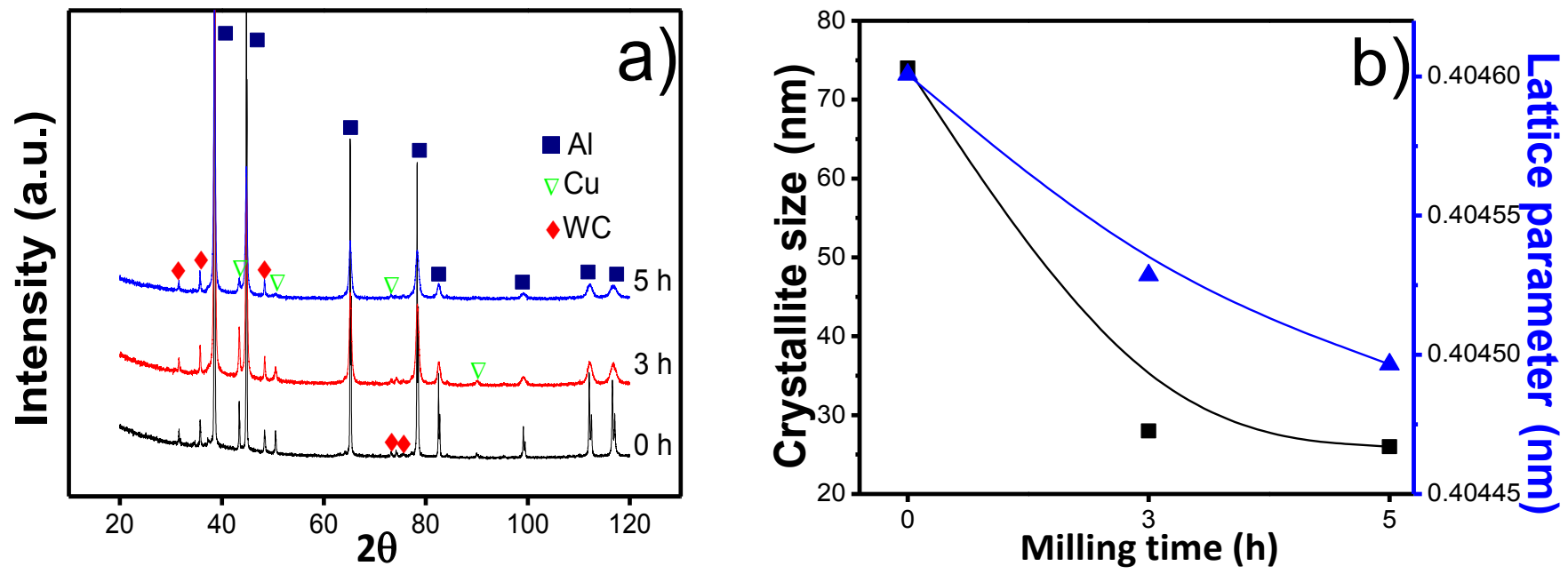

Figure 2. a) XRD Diffractograms of Al-Cu-Mg-WC alloy powder after 0,3 and $5 \mathrm{~h}$ of $\mathrm{mt}$ and b) crystallite size and lattice parameter of aluminum as a function of $\mathrm{mt}$. 